\title{
VII. Further remarks on Dr. Bradley's theorem for computing the astronomic refraction
}

\section{T.S. Evans LL.D. F.L.S.}

To cite this article: T.S. Evans LL.D. F.L.S. (1816) VII. Further remarks on Dr. Bradley's theorem for computing the astronomic refraction, Philosophical Magazine Series 1, 47:213, 23-33, DOI: $10.1080 / 14786441608638789$

To link to this article: http://dx.doi.org/10.1080/14786441608638789

里 Published online: 27 Jul 2009.

Submit your article to this journal $₫$

Џ Article views: 2

Q View related articles $\square$ 
is wonderful," says Professor Robison, "that in a matter of such unquestionable importance the public lins not enabled some persons of judgement to make proper trials;" and we camnot without regret remark, that nothing worth notice has been added to our experimental knowledge since Robison wrote his cxcellent articles on the Strength of Materials.

If the rule given above is correct, the following table will show the weight that would crush cylinders of different kinds of materinls.

\begin{tabular}{|c|c|c|c|}
\hline Material. & $\begin{array}{l}\text { Direct co- } \\
\text { hesson of } \\
\text { a square } \\
\text { inch. }\end{array}$ & $\begin{array}{l}\text { Nowht in pound: } \\
\text { that will crosh } \\
\text { cylinder an iucl. } \\
\text { in diameter. }\end{array}$ & $\begin{array}{l}\text { Weight in promes } \\
\text { ibat nill erush a } \\
\text { cylinder whose } \\
\text { bise is one foot } \\
\text { in area. }\end{array}$ \\
\hline $\begin{array}{l}\text { Cast iron ... } \\
\text { Lead ..... } \\
\text { Freestone . . } \\
\text { Fine freestone } \\
\text { Good brick.. }\end{array}$ & $\begin{array}{r}11,9 \\
50,000 \\
3,000 \\
1,000 \\
205 \\
280\end{array}$ & $\begin{array}{r}314,160 \\
18,819 \\
6,283 \\
1,238 \\
1,759\end{array}$ & $\begin{array}{r}57,600,000 \\
3,456,000 \\
1,152,000 \\
236,160 \\
322,500\end{array}$ \\
\hline
\end{tabular}

VII. Further Remarks on Dr. Braduex's Theorem for computing the Astronemic Refiation. By T. S. Evass, LL.D. F.L.S.

$\mathrm{T}$ with the astronomic refraction; and perhaps no other subject is so worthy their notice at this moment, since it is the freatest obstacle of any, to improvements and accuracy in that science. Much has lately been done towards an exact deternination of its quantity at all altitudes above the horizon, by the use of the modern circles of Ramsden, Troughton, aud other eminent instrument-makers. The great care with which these have bern divided, and may be adjusted; the minuteness with which they may be read off, by means of micrometers, placed in the microseopes; and the certainty wih which the ubject can be bisected, in the field of view, by using cobwchs, or perhaps the minute platina wires lately made by the ingenious Dr. Wollaston, give us great reason to hope, that with the zeal of our present best observers much time will not elapse, before the difficulties now met with in discovering the quantity of the refraction, will in a great measure, if not wholly, be removed.

Uf all the different formula that have hitherto been published, B 1 
it does not appear that any one of them at present will give the true refraction nearer than about six or seven seconds at ten degrees of altitude, and most of them reach to that extent with the same limits of error. It is therefore unnecessary to have recourse to the long and laborious methods that have been offered, when more simple ones will effect the purpose with equal exactness. Our attention should rather be directed to the improvement of some one of the number, that is easily computed so as to extend its application and bring it to correspond better in observations made at low altitudes. But if it should be found that the law of its progression does not admit of being expressed by a formula, we must endeavour to remedy the defect by means of a table; that will give its'quantity at all necessary intervals.

According to the theory published by Mr. Thomas Simpson, in his Mathematical Dissertations, and further improved by Dr. Bradley, which, with modern determinations of the coefficients, is the one now most commonly used in England, on account of its simplicity, the equation for the astronomic refraction is

$$
p \times \operatorname{tang} \cdot(Z . D-n r) \times\left(1+\frac{\dot{\beta}}{\beta}\right) \times\left(\frac{1}{1+m \dot{\theta}}\right)
$$

which is evidently of the indeterminate kind, since it contains no less than four unknown quantities, that require to be discovered from other sources. These are $p, n, r$, and $m$; of which the first, $p$, is the refraction at $45^{\circ}$ of altitude of the object above the horizon, taken at any given standard of temperature and density of the atmosphere. The second, $n$, is some multiple of the third, or -mean refraction $r$, by which the zenith distance of the ohject is to be diminished before its tangent is taken out of the tables.

From a comparison of the theory with some accurate observations lately taken, I have had reason to think that $n$ is not a constant imultiplier of $r$, as has hitherto been sipposed, but that it varies, according to some function of the altitude of the object above the horizon.

The fourth of these unknown coefficients, $m$, is the expansion of a volume of air, for each degree of ascent of Fahrenheit's thermometer; and the same comparison abovementioned, in conjunction with the latest and most exact experiments of two justly celebrated modern chemists has also furnished some strong reasons for doubting, whether the expansion for each degree of the thermometer is the same for all states of temperature, from the freezing to the boiling point.

This inquiry may, perhaps, by some persons be deemed interesting, as it points out a subject where the determinations of the chemist are corroborated by those of the astronomer.

These 
These two branches of philosophy are apparently very distinct from each other, and separated by boundaries that do not at first sight appear even to approximate. It is therefore pleasing to discover a case wherein one of them is capable of affording assistance to the other; as it show's their mutual dependence, and consequently the advantages of cultivating and improving at the same time all the departments of human knowledge.

By consulting Dr. Thomson's valuable Treatise of Chemistry, vol. i. p. 494, on the expansion of atmospheric air, we read as follows :

"From the experiments of Dalton and Gay-Lussac it appears that all gaseous bodies whatever undergo the same expansion by the same addition of heat, supposing them placed under similar circumstances. Gay-Lussac found that air by being heated from $32^{\circ}$ to $212^{\circ}$, expanded from 1000 to 1375 parts under a pressure $=0.76$ of a metre ( $=29.92152$ English inches). Mr. Dalton found that 1000 parts of air, heated from $55^{\circ}$ to $212^{\circ}$, expanded to 1325 parts. He found also, that the expansion of air is very nearly equable; or that the same increase of bulk takes place, by the same addition of caloric, at all different temperatures. The expansion from $55^{\circ}$ to $133 \frac{1}{2}^{\circ}$, was 167 parts ; and from $133 \frac{1}{2}$ to 212 it was 158 parts. He has also shown that the expansion of air follows a regular geometric progression, if we suppose that mercurv expands as the square of the temperature from the freezing point : and he has rendered it probable, that the expansion of water and mercury is as the square of the temperature of each, reckoning from their respective freezing points. He finds, if this law be supposed, that the expansion of water and mercury corresponds: hence he infers, that all liquids follow the same law; or that they expand as the square of the temperature, from the freezing point of each."

If we reduce these experiments to the same standard, and then bring their results into one point of view, they will be as follows :

First : M. Gay-Lussac found that air by being heated from $32^{\circ}$ to $212^{\circ}$ expanded from 1000 parts to 1375 parts. Therefore for 180 degrees it expanded $\frac{375}{1000}$ of the whole : consequently as $180: \frac{375}{1000}:: 1: \frac{375}{180000}=0.00208 \dot{3}$ the expansion for each degree of the thermometer when taken throughout the whole extent of the scale from the freezing to the boiling point.

Secondly: Mr. Dalton found that air when heated from $55^{\circ}$ to $212^{\circ}$ expanded from 1000 to 1325 parts: therefore, as 
$157: \frac{825}{1000}:: 1: \frac{325}{157000}=0.002070064$ the expansion for that part of the scale reckoning from $55^{\circ}$ to $212^{\circ}$

Thirdly: Mr. Dalton found that when the air was heated from $55^{\circ}$ to $133 \frac{1}{2}$ only, it expanded from 1000 to 1167 parts ; consequently as $78.5: \frac{167}{1000}:: 1:{ }_{78500}^{167}=0.0021273885$ the expansion for each degree of the scale from $55^{\circ}$ to $133 \frac{1}{2}^{\circ}$.

Fourthly: The same ingenious experimentalist found that for an accession of heat from $133 \frac{1}{2}$-to $212^{\circ}$ the increase of bulk was from 1000 to 1158 parts; we have therefore as $78 \cdot 5: \frac{158}{1000}:: 1$ : $\frac{158}{78500}=0.00201273885$, the rate of expansion reaching from $133 \frac{1}{2}$ to 212 : and by bringing these together for the purpose of more easy comparison, we find that

From $55^{\circ}$ to $133 \frac{1}{2}$, the rate of expansion is 0.002127389

$\begin{array}{ccccc}32 \text { to } 212 & \ldots & \ldots & \ldots & 0.002083333 \\ 55 \text { to } 212 & \ldots & . & \ldots & 0.002070064 \\ 133 \frac{\pi}{2} \text { to } 212 & \ldots & . & . & 0.002012739\end{array}$

The greatest rate of expansion in this statement is $0.0021273 \mathrm{S9}$, and the temperature corresponding is lower than either of the others, viz. from 55 to $133 \frac{1}{2}$. 'The least rate is 0.002012739 ; and its corresponding temperature is from $133 \frac{\mathrm{T}}{2}$ to 212 , which is the highest of all the four. Of the other two, that from 32 to 212 includes a lower part of the scale than the one reaching from 55 to 212 ; and we find the rate of expansion is proportionally greater. It therefore appears, that the rate of expansion for the low temperatures is greater than that for the high ones; and consequently $m$, the coefficient of $\theta$, in that part of the foregoing theorcm which depends on the heat of the amosphere, viz. $\frac{1}{1+m \theta}$ ought to be variable according to the different heights of the mercury in the thermometer.

Although the above table shows pretty clearly that the rate of expansion is greater in the low temperatures than in the ligh, yet there is not a sufficient number of them, nor are they made at the proper intervals to enable us to compute the exact law of this rate, for all degrees, from the freezing to the boiling point, which for the subject under consideration is very much to be desired.

These are the determinations of the chemists. Let us now endeavour to discover how far they are corroborated by the observations of the astronomer.

In the last communication which $\mathrm{Mr}$. Groombridge has furnished us with, on the subject of refraction (Phil.Trans. for 1814), if we arrange the values of $n$, determined by that gentleman, according to the different states of the thermometer, onitting those 
those that belong to very low altitudes as they are materially affected by other considerations they will be as follows:

\begin{tabular}{|c|c|}
\hline Therm. & Values of $n$. \\
\hline 32 & $3 \cdot 74129$ \\
34 & $3 \cdot 59582$ \\
36 & $3 \cdot 70809$ \\
36 & $3 \cdot 65835$ \\
37 & $3 \cdot 63139$ \\
39 & $3 \cdot 64778$ \\
39 & $3 \cdot 21379$ \\
\hline 40 & $3 \cdot 62402$ \\
40 & $3 \cdot 62441$ \\
40 & $3 \cdot 65160$ \\
42 & $3 \cdot 64000$ \\
43 & $3 \cdot 63706$ \\
43 & $3 \cdot 62255$ \\
\hline 53 & $3 \cdot 63505$ \\
53 & $3 \cdot 16032$ \\
54 & $3 \cdot 35247$ \\
55 & $3 \cdot 61333$ \\
57 & $3 \cdot 49971$ \\
59 & $3 \cdot 54668$ \\
\hline 60 & $3 \cdot 54576$ \\
61 & $3 \cdot 61064$ \\
62 & $3 \cdot 55849$ \\
\hline
\end{tabular}

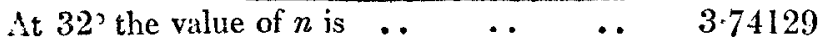

32 to 40 omitting the last $39 \quad \ldots \quad 3.66345$

From 32 to 40 including the last $39 \quad \ldots \quad 3 \cdot 59922$

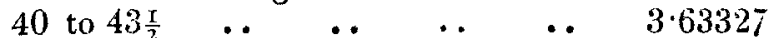

53 to 60 omitting the second $53 \quad$.. 352945

53 to 60 including the second $53 \quad$.. $\quad 346793$

60 to $62 \quad \ldots \quad$.. $\quad$. . . . 353763

A slight examination of the above values of $n$ will convince us that there is an evident change from $32^{\circ}$ to $60^{\circ}$. Now if in the preceding formula we omit the part

$$
p \times\left(1+\frac{\beta}{\beta}\right),
$$

or consider it as being constant; and take only the remaining part of the expression, viz.

$$
t,(Z . D-n r) \times\left(\frac{1}{1+m \dot{j}}\right),
$$




$$
\text { or, } t,(Z D-n r) \times(1-m \dot{\theta}) \text {, }
$$

and substitute for $n$ and for $\dot{\theta}$ their two extreme values taken from the foregoing table of means, we shall have in one instance,

and in the other,

$$
t,(Z D-3 \cdot 74 r) \times(1-m \times 32),
$$

\section{formula made for temperature zero.}

$t,(Z D-3.47 r) \times(1-m \times 56)$, supposing the

Now in these two equations, the lower the mercury is in the thermometer, the greater is the value of $n$ found to be: and the higher it is on the contrary, the less is the value of $n$ : but to obtain the two values of $n$ equal in the two equations, it is evident that the multiplier $m$ must be increased at 32 , and diminished at 56 ; which seems to be a further and interesting corroboration, of what was before stated, viz. that the rate of expansion for the low temperatures is greater than that for the high ones.

By carrying this mode of reasoning a little further, and supposing in the two last equations, that the values of $t,(Z D-n r)$ are constant, it would in that case be evident, that the variations of $m$ would be inversely as the numbers 32 and 56 ; or that the rate of expansion would be in the inverse proportion of the height of the thermometer, provided the refraction and the rest of the coefficients remained the same. But as this is not the case, and the result thus obtained is far greater than is proved by experiments, and also that the ratio of the two values of $m$, in the two equations, is considerably nearer a ratio of equality, it follows that the value of $\mathrm{n}$ musi also vary, and possibly, according to some function of $Z D$, or the zenith distance of the oijject.

The difficulty of determining the values of $m$, under all temperatures of the atmosphere, and of $n$ at all altitudes, above the horizon will, from this, become evident : and it shows that they can only be obtained by some such method as that of the least squares proposed by $M$. Lagrange ${ }^{*}$, and from a long series of observations taken at all periods of the year, in order to find them for the whole extent of the ranges of the barometer and thermometer.

Were all other circumstances to remain the same, and only the value of $m$ to change, we might easily obtain it in the following manner :

The mean refraction $r$ is to the apparent refraction $\xi$ as 1 to $\frac{1}{1+m \dot{\theta}}$, or $r: \rho:: 1+m \dot{\theta}: 1$; and therefore $r=\rho(1+m \dot{\theta})$, consequently $m=\frac{r}{e^{\dot{\theta}}}-\frac{1}{\dot{\theta}}$; and by taking the different

* New Method of determining the Orbits of Comets. Paris, 1806. 4to. 
values of $\rho$ and $\dot{\theta}$, as found from the observations, we may obtain that of $m$ for all heights of the mercury in the thermometer.

With respect to the value of $p, \mathrm{Mr}$. Delambre found it to be $60.499872^{\prime \prime}$ at 45 degrees of apparent altiturle, when the barometer stood at 29.92152 English inches, and Fahrenheit's thermometer at $32^{\circ}$. Mr. Groombridge found it $58 \cdot 132967^{\prime \prime}$ at the same altitude, when the barometer was $29 \cdot 60$ English inches, and the thermometer at $45^{\circ}$.

To compare these two viblues of $p$ together, it is necessary to reduce one of them to the tenor of the other. Thus Mr. Delambre's determination, when brought to the same state of the atmosphere as that of $\mathrm{Mr}$. Groombridge, will be

$$
69 \cdot 499872^{\prime \prime} \times \frac{29 \cdot 60}{29 \cdot 92152}\left(\frac{1}{1+(45-32) 0002}\right):=58.33311^{\prime \prime} .
$$

and $\mathrm{Mr}$. Groombridge makes his $58 \cdot 132967^{\prime \prime}$; the difference $0.200143^{\prime \prime}$ is small, and confirms the accuracy of the observations of both; yet small as it appears, it will very materially affect the refractions from $87^{\circ}$ downwards to the horizon.

It is much to be doubted, whether this theorem or anv other can be brought to agree with the utmost exactness in all cases with the refraction observed at very low altitudes, and for the following reasons :

The ray $\mathrm{P} \mathrm{S}$ in its progress through the atmosphere from the

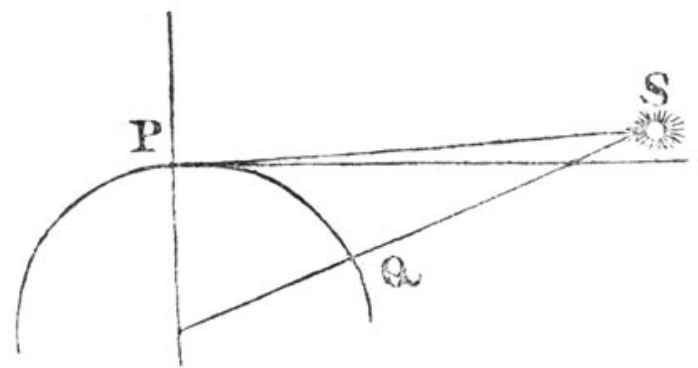

star $S$ to the observer $P$, has probably to encounter layers of air of various temperatures and densities, which differ considerably from that indicated by the barometer and thermometer fixed up for use at $P$, the station of the observer; therefore, to be enabled to form any just conjecture of the deviations which the ray may have undergone, we ought to know the state of the atmosphere all the way from $P$ to $S$; or at least we ought to be acquainted with the heat and density indicated by these two instruments along the surface of the earth, from the station of the observer at $P$ to $Q$, the point immediately beneath the object observed. 
It is well known that showers of rain often proceed in zones along the surface of the earth, in various directions; and should this have taken place across any part of the arc PQ, a short time previous to the observation being made, the evaporation that follows, by producing a greater degree of cold, will cause a considerable augmentation in the refractive power of the circumambient air.

A large surface of sand, situated any where along the $\operatorname{arc} \mathbf{P} \mathbf{Q}$ will, by absorbing a considerable portion of heat from the sun's rays, and afterwards continuing to restore it to the atmosphere, longer than the neighbouring soils that have absorbed less, by keeping up the rarefaction, bend the ray out of its course, in an opposite direction to that of the former cause.

A iarge wood or a marsh will also be the cause of deviation in the trajectory of the ray: and all these actions on its course will be the stronger the nearer it lies to the horizon, or in other words the less the altitude of the object.

Mr. Delambre, in the excellent T'reatise of Astronomy which he has lately published, makes the following remarks on the refraction at low altitudes.

"It follows from all this that Simpson's Formula and Bradley's Table will not agrce witl. the observations. There is an error of about $8^{\prime \prime}$ at $82 \frac{\mathrm{x}}{2} \mathrm{O}$, and no known table will agree with them. 'That of the Board of Longitude computed from Laplace's formula, and on the value which I found for the constant quantity $\alpha$, (the refraction at $45^{\circ}$ which is $p$ of our formula) agrees better, but the error is still from '2" to $3^{\prime \prime}$.

"I have already spoken of the uncertainty of observations of refraction in the neighbourhood of the horizon. I have remarked, from one day to the next, and in circumstances which were the same in appearance, that the refraction would vary from $15^{\prime \prime}$ to $20^{\prime \prime}$, without my being able to assign any cause; but the variations are still more sensible in the horizon, as we may judge from the following statement:

\begin{tabular}{|c|c|c|c|c|}
\hline $\begin{array}{c}\text { Compisted } \\
\text { zenith distance. }\end{array}$ & $\begin{array}{c}\text { Observed } \\
\text { zenith distance. }\end{array}$ & Refraction. & Barom. & $\begin{array}{l}\text { Therm. } \\
\text { of } 80 \text {. }\end{array}$ \\
\hline $90^{\circ} 44^{\prime} \quad 5 \cdot 4^{\prime \prime}$ & $90^{\circ} \quad 8^{\prime} 3$ & $35^{\prime} 2$ & $276 \cdot 0$ & 64 \\
\hline $\begin{array}{llll}90 & 33 & 39 \cdot 2\end{array}$ & $90 \quad 2 \quad 43.6$ & $3055 \cdot 6$ & $276 \cdot 0$ & 64 \\
\hline $90 \quad 33 \quad 9 \cdot 1$ & $\begin{array}{lll}90 & 2 & 12 \cdot 7\end{array}$ & $30 \quad 57$ & $27 \quad 7 \cdot 4$ & 64 \\
\hline $90 \quad 33 \quad 13 \cdot 0$ & $90 \quad 1 \quad 53$ & $31 \quad 19 \cdot 6$ & $276 \cdot 5$ & $20 \cdot 32$ \\
\hline 9027506 & 895436 & $33 \quad 14 \cdot 6$ & $278 \cdot 1$ & $11 \cdot 84$ \\
\hline $90 \quad 39 \quad 84.5$ & $90 \quad 4 \quad 37$ & $3457 \cdot 4$ & $27 \quad 6 \cdot 3$ & $19 \cdot 20$ \\
\hline
\end{tabular}

"All these observations were made in June at sunrise. From the 
the first to the second there was an interval of eight days, and of eleven from the second to the third. The barometer has scarcely varied at all, and the thermometer has varied but little, yet the refraction has varied 4 minutes at these zenith distances. According to our last tables the refraction changes from 11 " to $12^{\prime \prime}$ for each minute of variation in the zenith distance. That of Bradley and of all the other astronomers varies from $10^{\prime \prime}$ to $11^{\prime \prime}$. Supposing $11^{\prime \prime}$ of variation and reducing all these refractions to the astrotomic horizon, that is to $90^{\circ}$ of apparent zenith distance, we shall have for the horizontal refraetion,

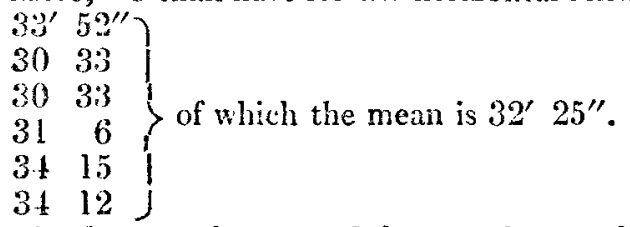

$r$ From the first to the second day we have a difference of $3^{\prime} 19^{\prime \prime}$, although the harometer aidl the thermometer are the sarre. From the second to the third, the refraction has not varied, although the thermometer has got up 4 degrees. The tivo last dars the refraction has only altered $3^{\prime \prime}$, although the thernometer has got up 7.36 degrees.

"We cannot therefore be certain of the mean to 2 minutes, which agrees nearly with that of Cassini. It is hardly probable that we shall ever be able to compute such anomalies; and what would they have been had I observed in winter?

"At $7 s^{\prime}$ I could not make the observations of different days agree nearer than about 6 " or " 7 " between the extreme values.

"At $77^{\circ}$ I have had variations of $10^{\prime \prime}$ and 11 ".

"At $79^{\circ}$ they were $15^{\prime \prime}$.

"At $82^{\circ}$ they differed as much as $36^{\prime \prime}$; that is, the table that I had constructed representing the observations of several days to $1^{\prime \prime}$ or $2^{\prime \prime}$ nearly, was found once in error $-17^{\prime \prime}$, and another time $+19^{\prime \prime}$.

"At $84^{\circ}$ I lave been more fortunate, the error was one half less.

"At $86^{\circ}$ the difference between the extremes was $30^{\prime \prime}$.

"At 88 ' the errors, which were nothing for several dais, increased then to $+15^{\prime \prime}$ and $-20^{\prime \prime}$.

"At $89^{\circ}$ from $-15^{\prime \prime}$ to $+30^{\prime \prime}$ ""

"The tables of Bradley and Mayer give still greater errors, so that it appears to me inpossible to make any good table for these lower degrees. But from the zenith to $32 x$, we may have a number of tables nearly all equally good.

"In the fifth book of Spccoln di Palermo by Piazzi, you may find a great number of observed refractions. I have recomputed all the calcliations, and have found then very accurate. Differences at least equal to mine, may be remalked among them. 
"In the observations of zenith distances of terrestrial ob. jects, I have repeatedly noticed, that at the setting of the sun the refraction increased from 2 minutes to $2 \frac{1}{2}$ minutes; so that objects which were hid during the whole of the day, became visible in the evening. (See Base du Syst. Metr. Decimal, t. i. pag. 157, 159, and 165). I have never seen that the state of the hygrometer had any sensible influence on the terrestrial refraction; (ibid. page 166). Messrs. Laplace, Gay-Lussac and Biot have proved, that it does not produce any change in the astronomic refraction."-Delambre's Astr. tom. i. p. 318.

It is therefore evident, that to complete the solution of this problem much yet remains to be done. From the present view of the subject, it would appear as if the best mode would be, to take successive altitudes of objects with an accurate altitude and azimuth instrument, from the times of their rising in the eastern part of the horizon, till they set in the western part, giving the preference to those that pass the meridian nearest to the horizon below the pole: and to repeat the observations at various seasons of the year under a great variety of densities and temperatures of the atmosphere. Each single observation should be recorded, and not the mean of a number, as is usual for other purposes in astronomy. They should be taken in as quick succession near the horizon as accuracy will admit; but higher up a smaller number will be sufficient. The meridional altitude should also be taken with great care above the pole when the state of the weather is favourable, as that will materially assist in the calculation.

By this means, the latitude of the place being known, together with the declination and azimuth of the object, or the time when the observation was made, we may, by computation, obtain its true altitude; and the difference between this and the observed altitude will be the refraction at that point. In this manner, from a number of observations, we shall obtain the refraction at every degree of altitude, from the horizon to the zenith; and taking them under different densities and temperatures, we may by equations of condition, or the method of the least squares, develop the whole, and assign, with the utmost accuracy, to each unknown quantity in the formula, its due magnitude in all its variety of circumstances.

The method is, it must be acknowledged, very laborious, and will require much time, both in making the observations and in conputing them; but the advantages which astronomy will derive from an exact determination of this equation, are proportionally great. Did the duties of my situation afford sufficient leisure, and the smoke of London permit the observations to be made, I should feel the utmost gratification in performing thi, labour, tedious as it appcars to be. 
Thus I have endeavoured to show in what points this theorem is defective, not with any view to depreciate its value, but to assist in rendering it more perfect. It is the nos simple one we have: and when the four unknown coeficionts beforementioned, can be ascertained for all altitudes, densities and temperatures, a great obstacle to improvement will be renoved, and the future progress of astronomy much facilitated.

Christ's llospital, Nov. 15, 1815.

\section{On the Mctallic Salts.}

\section{To Mr. Tilloch.}

Sin, - I REg leave to obtrude myelf again on your notice, to offer a few remarks on the metallic salts, in reply to the answer of your correspoutent H. (p. $2 t 5$, vol. xlvi,) to iny paper (p.44 same volume). This I feel myself impelled to do, not only from the importance of the subject, but from some stratements which H. has adduced as unobjectionable facts in support of the theory contained in his former paper. Bofure I procect, hovever, it will be recessary to define the impert of the words fiee and excess as hereafier ued, philosophinel discussions requiring a strict adherence to terms. Inteed an omistion of this kind has produced some degree of displensure in you correspondent, who objects to my nsing the words fice and caress indiscriminately, which alone should be attributed to the ditherent opinions we entertain of the subject. By acid in excess I mean, when the superabundance of acid is chemiciaty combined with the base, and forms a constituent part of the salt. Fy free acid, when mechanically united ol only athering to the salt.

The inguiry is, if an excess of acid is really essential to the existence of all metallic salts. The arguments on one side tend to show that it is essential, because their solutions constantly indicate aedity with the test; on the other side it is maintaired, that alhough free acid may, and in general appears to be necessary for solution, yet it is not required for the existence of the sait.

As I endeavoured to prove that solubility was inereased by an increase of acid, H. in his answer draws the conclusion that, if such was the case, a salt would not he precipitated by acid in any proportion, and that the acid must be the solvent. And he alleges in opposition, that the greater proporsion of fiee acid, rather than render a metalic salt more solnble, will in most instances precipitate it, and that the water alone was the solvent;

Vol. 17. No. 213. Jan. 1816. i otherwise, 